\title{
Thymoquinone-induced conformational changes of PAK1 interrupt prosurvival MEK-ERK signaling in colorectal cancer
}

\author{
Chirine El-Baba', Vijayalakshmi Mahadevan², Fabian B Fahlbusch³, Suma Mohan S², Tilman T Rau', \\ Hala Gali-Muhtasib ${ }^{4}$ and Regine Schneider-Stock ${ }^{1 *}$
}

\begin{abstract}
Background: Thymoquinone (TQ) was shown to reduce tumor growth in several cancer models both in vitro and in vivo. So far only a few targets of TQ, including protein kinases have been identified. Considering that kinases are promising candidates for targeted anticancer therapy, we studied the complex kinase network regulated by TQ.

Methods: Novel kinase targets influenced by TQ were revealed by in silico analysis of peptide array data obtained from TQ-treated HCT116wt cells. Western blotting and kinase activity assays were used to determine changes in kinase expression patterns in colorectal cancer cells (HCT116wt, DLD-1, HT29). To study the viability/apoptotic effects of combining the PAK1 inhibitor IPA-3 and TQ, crystal violet assay and AnnexinV/PI staining were employed. Interactions between PAK1 and ERK1/2 were investigated by co-immunoprecipitation and modeled by docking studies. Transfection with different PAK1 mutants unraveled the role of TQ-induced changes in PAK1 phosphorylation and TQ's effects on PAK1 scaffold function.

Results: Of the 104 proteins identified, 50 were upregulated $\geq 2$ fold by TQ and included molecules in the AKT-MEK-ERK1/2 pathway. Oncogenic PAK1 emerged as an interesting TQ target. Time-dependent changes in two PAK1 phosphorylation sites generated a specific kinase profile with early increase in PPAK ${ }^{\text {Thr212 }}$ followed by late increase in PPAK ${ }^{\text {Thr } 423}$. TQ induced an increase of pERK1/2 and triggered the early formation of an ERK 1/2-PAK1 complex. Modeling confirmed that TQ binds in the vicinity of Thr212 accompanied by conformational changes in ERK2-PAK1 binding. Transfecting the cells with the non-phosphorylatable mutant T212A revealed an increase of pPAK ${ }^{\text {Thr }}{ }^{23}$ and enhanced apoptosis. Likewise, an increase in apoptosis was observed in cells transfected with both the kinase-dead K299R mutant and PAK1 siRNA. Using structural modeling we suggest that TQ interferes also with the kinase domain consequently disturbing its interaction with PPAK ${ }^{\text {Thr } 423}$, finally inhibiting MEK-ERK1/2 signaling and disrupting its prosurvival function. pERK1/2 loss was also validated in vivo.

Conclusions: Our study shows for the first time that the small molecule TQ directly binds to PAK1 changing its conformation and scaffold function. Because TQ affects the central RAF/MEK/ERK1/2 pathway, the combination of TQ with targeted therapies is worth considering for future anticancer treatments.
\end{abstract}

Keywords: Thymoquinone, PAK1, ERK1/2, Colorectal cancer, Scaffold function, Kinome analysis, Apoptosis

\footnotetext{
* Correspondence: regine.schneider-stock@uk-erlangen.de

'Experimental Tumorpathology, Institute of Pathology, Friedrich-Alexander

University Erlangen-Nürnberg (FAU), Erlangen, Germany

Full list of author information is available at the end of the article
} 


\section{Background}

Colorectal cancer (CRC) affects yearly more than 1 million people worldwide [1], therefore there is constant need to achieve more effective cures. Over the recent years naturally occurring compounds have received increasing attention because of their anticancer effects [2]. Thymoquinone (TQ), the active compound extracted from Nigella sativa, is a very promising anticancer drug, whether used separately or in combination with conventional medicines [2-7]. Interestingly, TQ was found to have only limited toxicity to normal intestinal cells in vitro [8] and not to affect the survival or body weight of animals when used at doses up to $25 \mathrm{mg} / \mathrm{kg}$ in colorectal cancer animal models $[9,10]$. Previous work documented TQ's growth inhibitory and apoptosis triggering effects on colon and other solid tumors such as uterine sarcoma, breast, and pancreatic cancer in a dose- and time-dependent manner [9,11-14]. Moreover, TQ was shown to reduce tumor growth and to induce apoptosis in various murine cancer models $[5-7,10,15,16]$. So far, the anticancer mechanism of TQ is not fully understood; however, several modes of action have been described depending on the stimulus and the cellular context [2].

Protein kinases, the protagonists of phosphorylation, commonly work in complex networks and have become novel candidates for targeted therapy. There are a few studies describing the involvement of TQ in the regulation of kinases i.e. AKT1 [2] , JAK2 [17], JNK [8], IKKb [18], ERK2 [8], CHEK1 [9] andPlk1 [19]. Most of these kinases are frequently deregulated in colon cancer. In the last 10 years several kinase inhibitors have been clinically tested or are currently undergoing clinical trials in targeted therapy [20]. Such therapy blocks the growth and spread of cancer by specifically interfering with molecules affecting tumor cell proliferation and progression. In colorectal cancer we have shown that kinases such as c-Jun N-terminal kinase (JNK) and the prosurvival extracellular-signal-regulated kinase (ERK) were activated under TQ treatment before the onset of apoptosis [8]. The TQ resistance observed in HCT116 p53-/cells was associated with an upregulation of CHEK1, a serine/threonine kinase cell cycle checkpoint mediator, indicating an inefficient defense mechanism against TQinduced DNA damage when p53 is absent [9].

So far despite a few reports, the interaction of TQ with the kinase network of colon cancer cells is only poorly understood. Kinase signaling has been extensively investigated in the last decade and new techniques of quantitative proteomics have been developed simplifying the study of complex systems. Thus we performed a quantitative phospho-proteomic analysis to identify new targets in TQ- treated HCT116wt colorectal cancer cells. For the first time we show a direct binding of the plant derived small molecule TQ to the PAK1/ERK1/2 kinase complex leading to conformational changes in protein structures and consequently to apoptosis.

\section{Results and discussion}

Identification of new TQ targets by peptide array analysis Kinome analysis allows the characterization and quantification of the phosphorylation profile of a given kinase target under various experimental conditions. Using a peptide array, the treatment of colorectal HCT116wt cells with $40 \mu \mathrm{M}$ TQ for $24 \mathrm{~h}$ led to the identification of 104 proteins with a significant phosphorylation upregulation, among which were 50 proteins and kinases upregulated by $\geq 2$ fold (out of 1152 kinase substrate peptides). Many of these proteins were previously described as TQ targets (such as p21 ${ }^{\mathrm{Cip} 1}, \mathrm{p} 53$, ERK or NFkB) verifying the feasibility of the array data (Additional file 1: Table S1). The analysis of the phosphorylation motifs of all 104 candidates (Figure 1A) showed that TQ had a propensity for serine phosphorylation as well as an $80 \%$ probability to induce phosphorylation of a neutral polar amino acid ( $\mathrm{S}$ group). In silico analysis revealed that the most influenced pathways (Figure 1B) and networks (Figure 1C,1D) were those involved in cancer, cell cycle, cell death, and survival mechanisms. Moreover 24 of the top 50 candidate proteins were grouped into the cancer-related networks "cytoskeleton", "PI3K/AKT" and "Wnt signaling" (Table 1). The Venn-diagram for the most relevant biological functions identified 11 TQ-modulated proteins that are common in apoptosis, proliferation, and inflammation pathways. Besides the epigenetic marker CEBPB, the analysis included key molecules in the AKT-MEK-ERK pathway, a central signaling network for current targeted therapies (Figure 1E). With a fold-change of 2.12, p21 protein (Cdc42/Rac)-activated kinase 1 (PAK1) was an appealing candidate considering its role in cell growth, invasion, cell migration, cell survival, mitosis and cytoskeletal remodeling of cancer cells $[21,22]$. Recently PAK1 was considered a novel subject for targeted cancer therapeutic approaches [23]. Furthermore for the first time, PAK1 has been identified as a TQ target. An extensive pathway mapping of genes differentially phosphorylated by TQ at $24 \mathrm{~h}$ and subsequent pathway annotation clustering resulted in 5 significant pathway based clusters. It is interesting that PAK1 was mostly associated with AKT1 and RAF1 (Table 2) in all the pathways in the Annotation cluster3. The top 4 pathways obtained through clustering approach (T-cell receptor signaling, angiogenesis, MAPK and chemokine signaling) also included PAK1 making it the target of our more detailed study of TQ action.

\section{TQ effect on PAK1 phosphorylation}

In HCT116wt cells, the TQ-induced activation of pPAK $1^{\text {Thr212 }}$ observed in the array analysis was verified by western blotting (Figure 2A). Although PAK1 has several different phosphorylation sites, only PAK $1^{\text {Thr212 }}$ was 


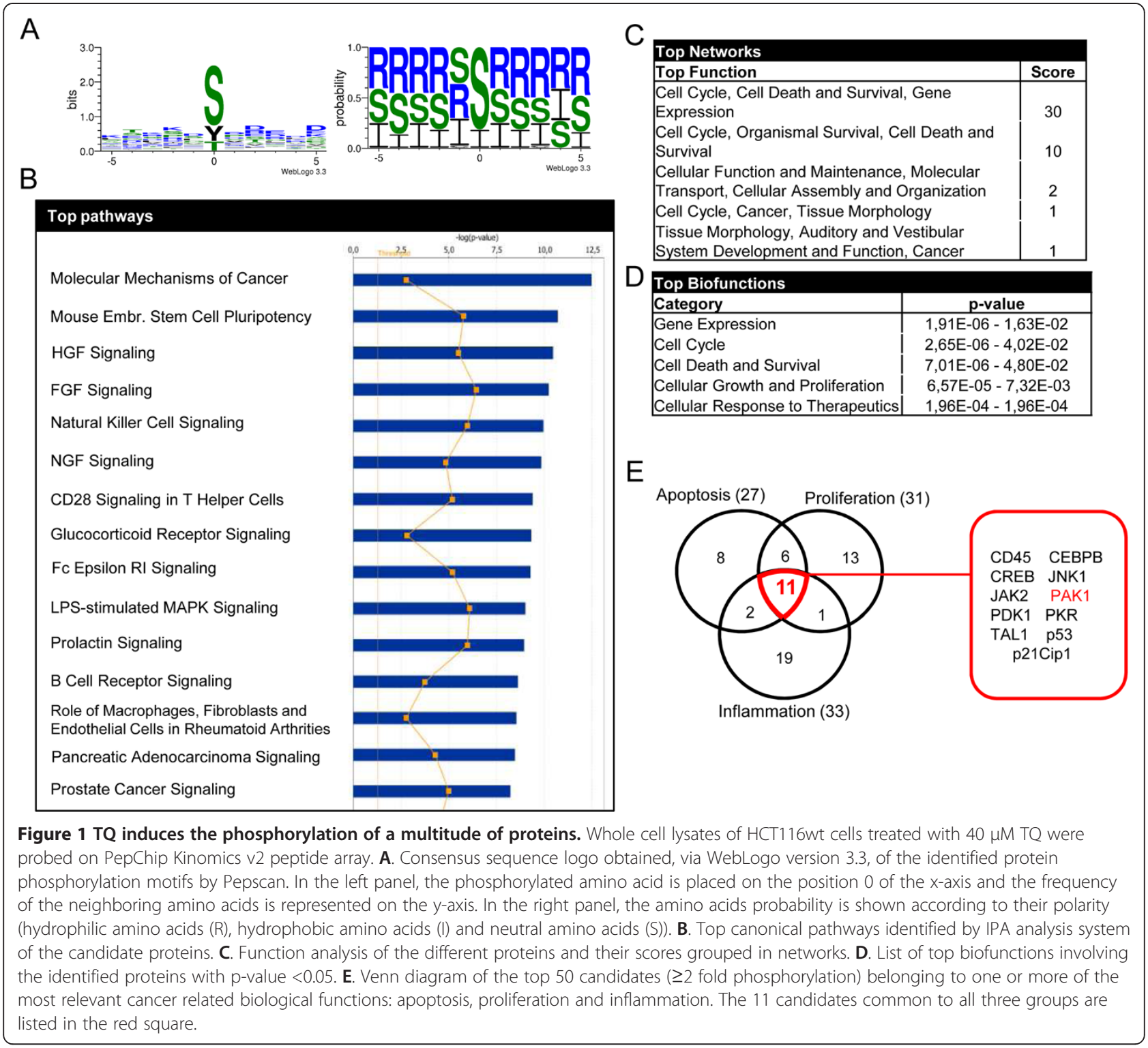

spotted on the PEPSCAN peptide array. In addition, we investigated two other well-studied phosphorylation sites: pPAK $1^{\text {Thr423 }}$ and PPAK $1^{\text {Ser144 }}$, by western blotting. Timedependent changes in the expression patterns of pPAK $^{\text {Thr212 }}$ and pPAK1 ${ }^{\text {Thr423 }}$ generated a specific kinase profile at early and late time points after TQ exposure. While pPAK1 $1^{\text {Thr212 }}$ showed a fast induction at 1 and $3 \mathrm{~h}$, pPAK1 ${ }^{\text {Thr423 }}$, found within the activation loop of PAK1, increased at $24 \mathrm{~h}$ (Figure $2 \mathrm{~A}$ ). In contrast, pPAK1 ${ }^{\mathrm{Ser} 144}$ and total PAK1 levels did not change over time (Figure 2A). Investigating another colorectal cancer cell line, DLD-1 showed the same profile of pPAK $1^{\text {Thr } 212}$ and pPAK $1^{\text {Thr } 423}$ regulation over time (Figure $2 \mathrm{~B}$ ). As expected, the TQ resistant HT29 cells [8] showed a different kinase profile where both pPAK1 $1^{\text {Thr212 }}$ and pPAK1 ${ }^{\text {Thr423 }}$ levels increased at the same time from 3 to $6 \mathrm{~h}$ and decreased at $24 \mathrm{~h}$ (Figure 2C).
TQ is a possible PAK1 inhibitor

To further understand the role of PAK1 in TQ-induced apoptosis, we used 1,1'-disulfanediyldinaphthalen-2-ol (IPA-3), the allosteric inhibitor of PAK1. IPA-3 prevents pPAK $1^{\text {Thr423 }}$ phosphorylation by targeting the autoregulatory site and disrupting the functional interaction between PAK1 and Cdc42 in addition to inhibiting the activity of other kinases [23,24]. Here we show that TQ did not change the activity of AKT2, GSK $\alpha$, GSK $\beta$ and p38, suggesting that this molecule might be more specific than IPA3 in interacting with PAK1 (Additional file 2: Figure S1). In addition, we performed a crystal violet viability assay and obtained an $\mathrm{IC}_{50}$ of $141 \mu \mathrm{M} \pm 30.7$ in normal intestinal epithelial HCEC cells in comparison to an $\mathrm{IC}_{50}$ of $50 \mu \mathrm{M} \pm 6$ in HCT116 tumor cells (Additional file 3: Figure S2), thus confirming the limited toxicity of TQ to normal cells. 
Table 1 Identified TQ targets belonging to cancer-related pathways

\begin{tabular}{|c|c|c|c|c|}
\hline Network & Identified substrate & Phospho site & Prot ID & Folds up $(24 \mathrm{~h})$ \\
\hline \multirow[t]{6}{*}{ Cytoskeleton } & EphB1 & Y594 & NP_004432 & 2.93 \\
\hline & Lamin A/C & S22 & CAA27173 & 2.45 \\
\hline & MAP2V & S1679 & NP_114034 & 2.30 \\
\hline & Syntaxin $1 \mathrm{~A}$ & S14 & NP_004594 & 2.22 \\
\hline & Lamin B1 & S395 & NP_005564 & 2.12 \\
\hline & SNAP23 & T24 & NP_003816 & 2.08 \\
\hline \multirow[t]{12}{*}{ PI3K/AKT } & Lck & S158 & AAH13200 & 3.45 \\
\hline & HSP22 & S14 & NP_0055180 & 3.32 \\
\hline & PKR & T451 & NP_002750 & 3.92 \\
\hline & Beta-2-adrenergic receptor-B2AR & S262 & NP_000015 & 2.80 \\
\hline & AKT1 & Y326 & NP_005154 & 2.22 \\
\hline & Bone marrow kinase BMX-ETK & Y40 & AAC08966 & 2.16 \\
\hline & Glucocorticoid receptor & S211 & NP_000167 & 2.15 \\
\hline & PAK1 & T212 & AAC24716 & 2.12 \\
\hline & Nitric oxide synthase 1 & S852 & NP_000611 & 2.09 \\
\hline & $\mathrm{CHOP}$ & S79 & NP_004074 & 2.08 \\
\hline & Metabotropic glutamate receptor 1 & T695 & AAA87843 & 2.05 \\
\hline & RAF1-c-RAF & S43 & NP_002871 & 2.00 \\
\hline \multirow[t]{6}{*}{ Wnt } & Beta-catenin & Y142 & NP_001895 & 2.89 \\
\hline & T-cell transcription factor 4 & S60 & NP_110383 & 2.59 \\
\hline & $\mathrm{N}-\mathrm{myc}$ & S263 & NP_005369 & 2.43 \\
\hline & L1 cell adhesion molecule & S1152 & NP_000416 & 2.25 \\
\hline & APC & S2054 & NP_000029 & 2.06 \\
\hline & МАР3К7-ТАK1 & S192 & NP_663304 & 2.01 \\
\hline
\end{tabular}

Table 2 Pathway mapping of TQ-phosphorylated targets by Annotation cluster3

\begin{tabular}{lccc}
\hline \multicolumn{1}{c}{ Database } & Pathway & $\mathbf{p}$-Value & Genes identified by peptide array \\
\hline KEGG_PATHWAY & T cell receptor signaling pathway & 0.001971 & PDK1, AKT1, RAF1, PAK1*, MAP3K7 \\
PANTHER_PATHWAY & Angiogenesis & 0.008722 & AKT1, TCF7L2, APC, RAF1, PAK1, CTNNB1, \\
KEGG_PATHWAY & MAPK signaling pathway & NOS1 \\
KEGG_PATHWAY & Chemokine signaling pathway & 0.041478 & MAX, AKT1, RAF1, PAK1, MAP3K7 \\
KEGG_PATHWAY & Renal cell carcinoma & 0.042726 & AKT1, CCR2, RAF1, PAK1 \\
PANTHER_PATHWAY & Ras Pathway & 0.053539 & AKT1, RAF1, PAK1 \\
BIOCARTA & Influence of Ras and Rho proteins on G1 to S Transition & 0.055681 & AKT1, RAF1, PAK1, MAP3K7 \\
KEGG_PATHWAY & ErbB signaling pathway & 0.079412 & AKT1, RAF1, PAK1 \\
KEGG_PATHWAY & Focal adhesion & 0.091138 & AKT1, RAF1, PAK1 \\
KEGG_PATHWAY & Fc gamma R-mediated phagocytosis & 0.093575 & AKT1, RAF1, PAK1 \\
BIOCARTA & MAPKinase Signaling Pathway & 0.094598 & MAX, RAF1, PAK1, MAP3K7 \\
PANTHER_PATHWAY & Inflammation mediated by chemokine and cytokine signaling & 0.229979 & AKT1, CCR2, RAF1, PAK1, MAP3K7 \\
PANTHER_PATHWAY & pathway & 0.27141 & AKT1, RAF1, PAK1 \\
\hline
\end{tabular}

*PAK1 is given in bold letters. 


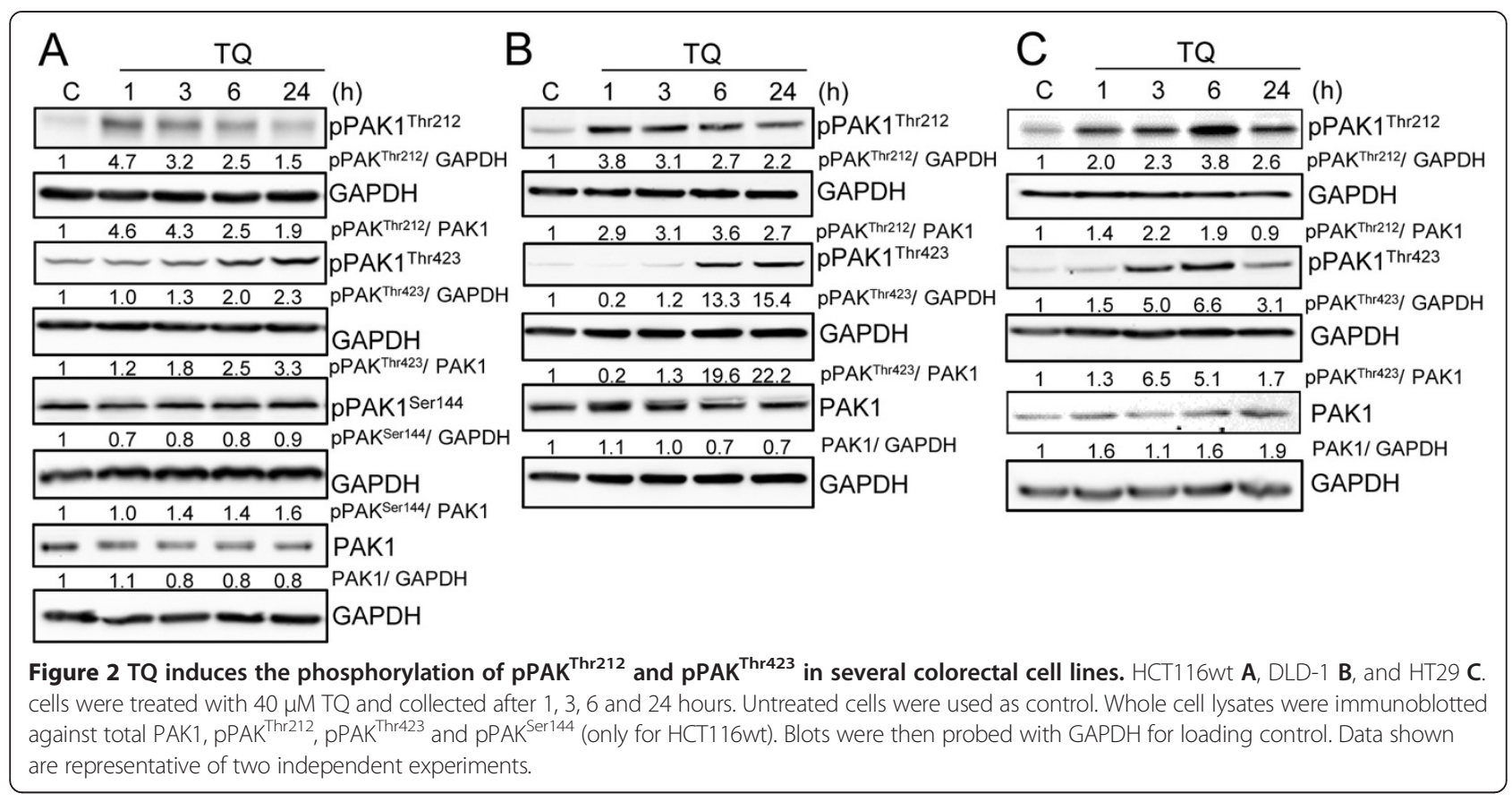

Since IPA-3 does not inhibit already activated PAK1, HCT116wt cells were pre-incubated with IPA-3 for $1 \mathrm{~h}$ and then stimulated with $40 \mu \mathrm{M} \mathrm{TQ}$ (Figure 3). Crystal violet staining showed that $30 \%$ of the cells were dead after $10 \mu \mathrm{M}$ IPA-3 (Figure 3A). Interestingly, the combination of TQ and IPA-3 $(10 \mu \mathrm{M})$ caused significantly more cell death and decreased cell viability by $70 \%$ (Figure $3 \mathrm{~A}$ ). AnnexinV/PI staining revealed that most dead cells were in late apoptosis (Figure 3B). TQ induced the "apoptotic" cleavage of PARP ( $89 \mathrm{kDa}$ fragment) at $24 \mathrm{~h}$, whereas in response to IPA-3 the cleavage was stronger and occurred earlier at $6 \mathrm{~h}$ (Figure 3C). Furthermore, transfection with kinase-dead dominant negative K299R mutant led to a larger increase in PARP cleavage showing more apoptosis when the kinase activity is lost (Figure 3D). Similarly, PAK1 siRNA transfection of cells followed by TQ treatment induced an increase in the pro-apoptotic response (Figure 3E).

In a next step, we determined changes in the expression of the different phosphorylation sites of PAK1 in IPA-3 and/or TQ treated cells (Figure 3F). As expected, pPAK $1^{\text {Thr } 423}$ protein level decreased when IPA-3 was combined with TQ at 3 and $6 \mathrm{~h}$ but this decrease was not sustained at $24 \mathrm{~h}$. To further understand this finding, we modeled the interaction between IPA-3, PAK1 and TQ. Docking IPA-3 to PAK1 (Additional file 4: Figure $\mathrm{S} 3 \mathrm{~A}$ ) revealed that IPA-3 binds to the CRIB motif (75-90) in the autoregulatory region of PAK1 dimer in a mode that enhances the interaction between both monomers (binding site first monomer: His83 and Gly98, second monomer: Met99). When TQ is docked into the IPA-3-bound conformation, IPA-3 still binds with both monomers. TQ also interacts with residues of both PAK1 monomers in the auto-inhibited dimer conformation (Additional file 4: Figure S3B and Additional file 5: Table S2). In this binding mode, TQ interaction with the kinase inhibitory segment of PAK1 (Asn38 residue) possibly causes the masking of the PAK1 activation loop and prevents the action of IPA-3 on Thr423 (Additional file 4: Figure S3).

The phosphorylation of pPAK1 $1^{\text {Thr212 }}$ in TQ and IPA-3 co-treated cells showed a remarkable increase in comparison to TQ alone (Figure 3F). This was surprising considering that IPA-3 only interrupts the interaction between Cdc42 and the autoregulatory site at Thr423 residue of PAK1 $[24,25]$. Knowing that PPAK1 ${ }^{\text {Thr212 }}$ is a major target of ERK2 [26], we further studied the role of ERK1/2/PAK1 interaction in response to TQ.

\section{TQ triggers conformational changes in PAK1 and induces ERK1/2-PAK1 binding}

In a next step we investigated the effect of TQ on ERK1/2 in HCT116wt cells. Kinase activity assay revealed that ERK1/2 activity significantly increased after $1 \mathrm{~h}$ of TQ treatment (Figure 4A). This was confirmed by western blotting, where pERK1/2 level was elevated at the same time point followed by a later decrease to normal levels (Figure 4B). In addition to the previously published increase in TUNEL and cleaved caspase-3 [10], immunohistochemical staining of the prosurvival pERK1/2 was significantly $(\mathrm{p}<0.05)$ lost in the nuclei of the TQ treated tumor xenografts (Figure 4C and Additional file 6: Figure S4).

Furthermore, time course analysis of $\mathrm{pPAK}^{\mathrm{Th} 212}$ and pERK1/2 levels at early time points revealed that PPAK $^{\text {Thr212 }}$ 


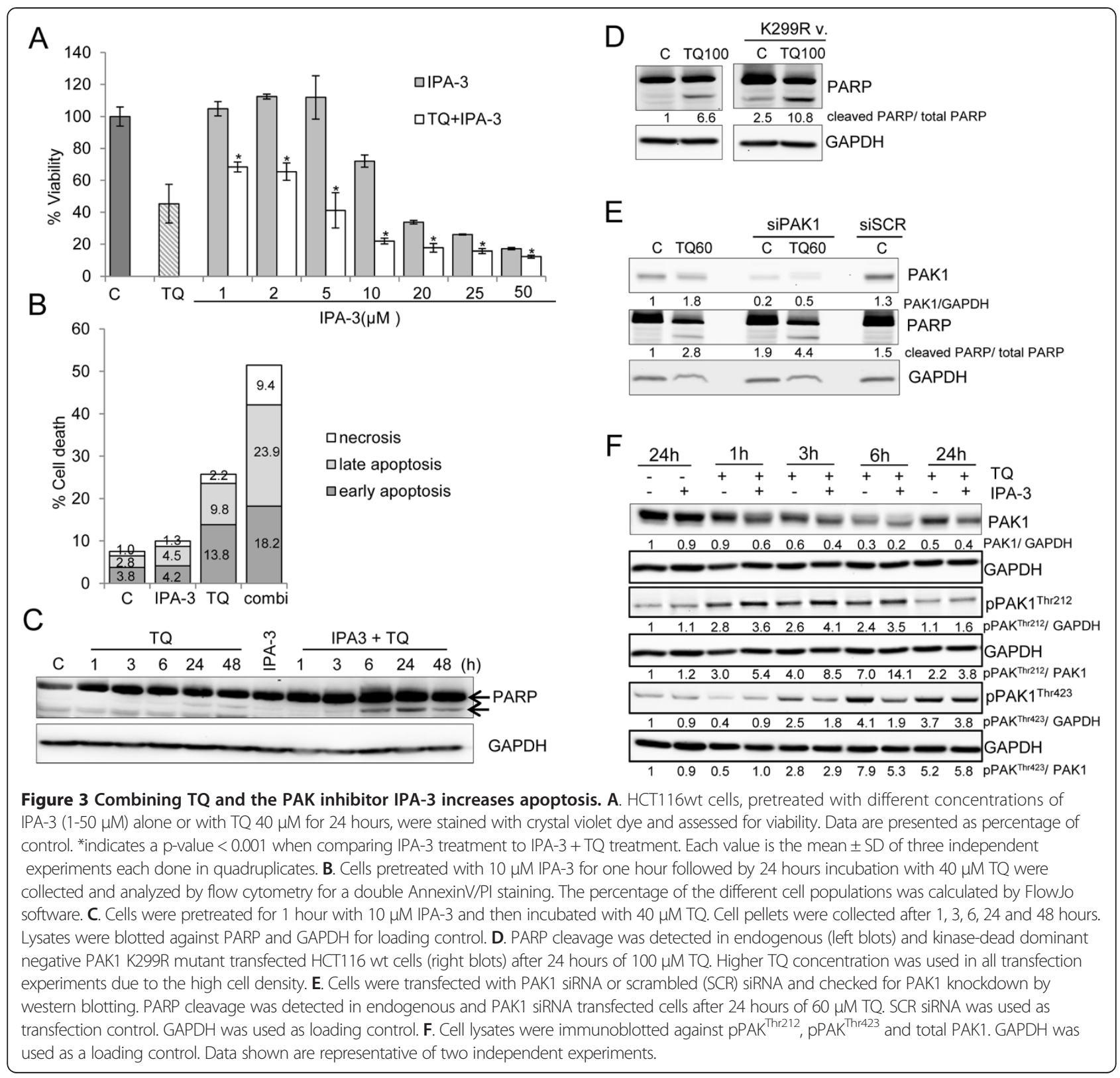

increase can be observed as early as $30 \mathrm{~min}$ whereas pERK1/2 increase started after $45 \mathrm{~min}$ of TQ treatment (Additional file 7: Figure S5). This suggests an involvement of other kinases in the phosphorylation of PAK1 at the Thr212 site in response to TQ. Interestingly, coimmunoprecipitation studies showed that TQ induced the formation of a PAK1 and ERK1/2 complex (Figure 4D). To better understand the nature of ERK1/2/PAK1 interaction in response to TQ, we modeled the PAK1-TQ interaction by docking PAK1 and TQ and identified a possible ligand binding site at the vicinity of Thr212 (Figure 5A) with a docking score of -2.316 (Additional file 5: Table S2) [27-30]. The energy of ERK2 bound to PAK1 conformation changed in the presence of TQ from $-21883 \mathrm{kcal} / \mathrm{mol}$ to $-22076 \mathrm{kcal} / \mathrm{mol}$ suggesting that TQ strengthens ERK2 binding to PAK1 [31]. It may also be noted from Figure $5 \mathrm{~B}$ and Figure $5 \mathrm{C}$ that ERK2 binds in a different mode to PAK1 in the presence of TQ. ERK2 binding to a different conformation of PAK1 may prevent ERK2 from phosphorylating the Thr212 of PAK1. This could explain why pPAK $1^{\text {Thr212 }}$ levels decrease over time in response to TQ (Figure 2A). Furthermore, TQ-induced pERK1/2 levels were not reduced by IPA-3 treatment, instead ERK1/2 activity was further enhanced from $1 \mathrm{~h}$ to $6 \mathrm{~h}$ when TQ was combined with IPA-3 (Figure 4B), suggesting the involvement of other upstream kinases in phosphorylating ERK1/2. If the TQ-triggered closer binding between ERK1/2 and PAK1 is 
A

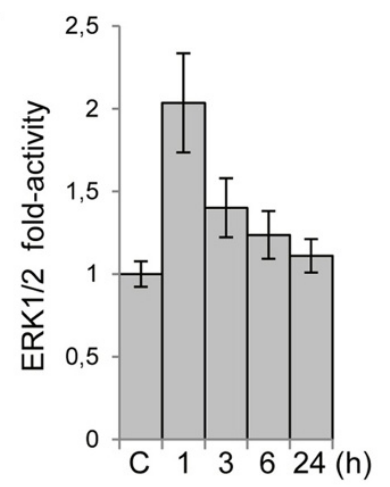

C

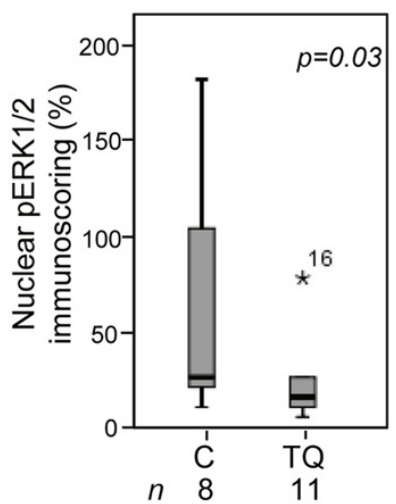

B

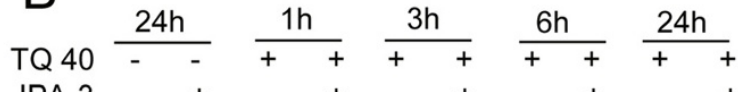
IPA-3 - + + $-\quad+\quad-\quad+\quad-\quad+\quad-\quad+$

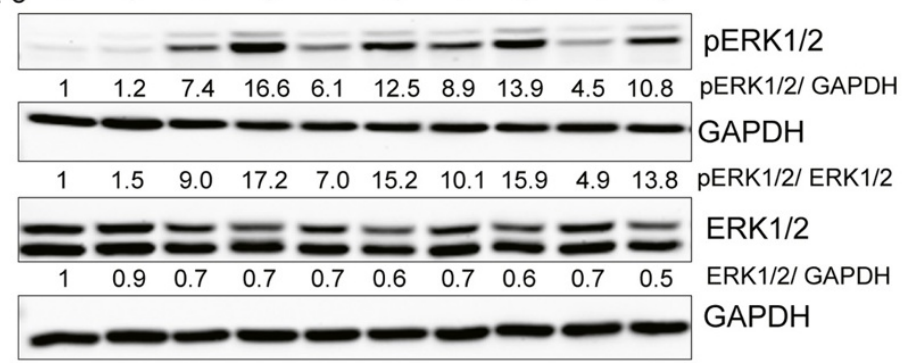

D

IP: PAK 1 $\frac{\text { Lysate }}{\text { C } 24 h}$ WB: PAK1 WB: ERK1/2
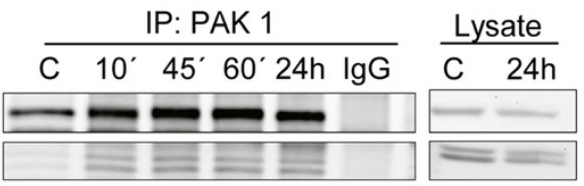

$\lg G$

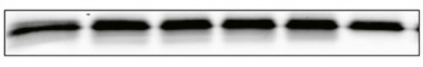

TQ 60

IP: ERK $1 / 2$ $\frac{\text { Lysate }}{\text { C } 24 \mathrm{~h}}$ WB: ERK1/2 WB: PAK1 $\lg G$

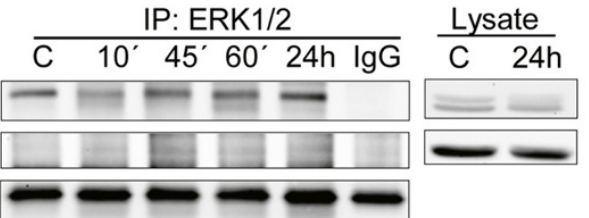

E

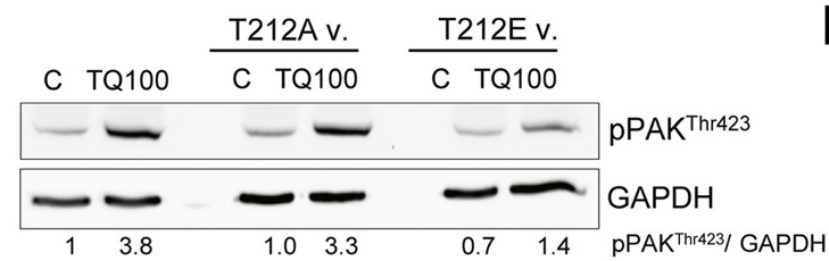

$\mathrm{F}$

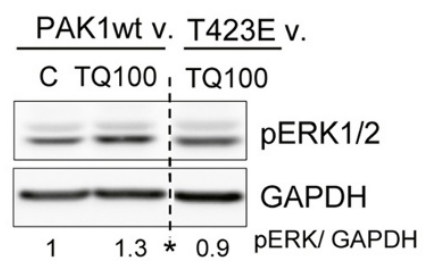

$G$

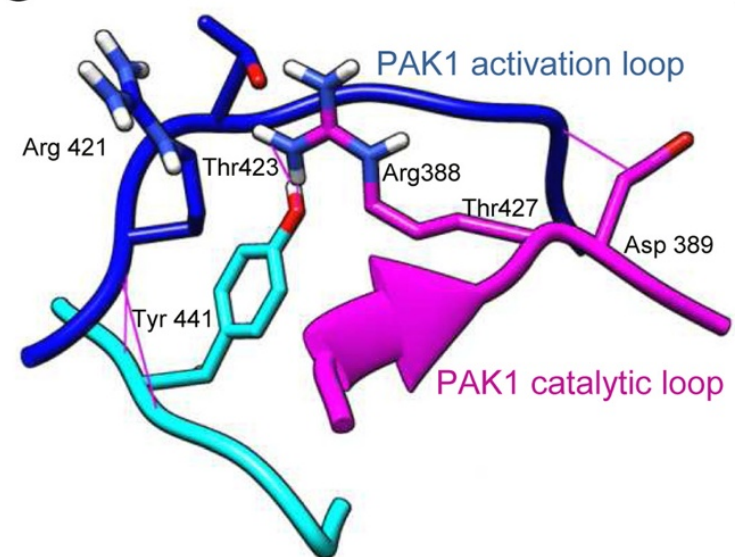

$\mathrm{H}$

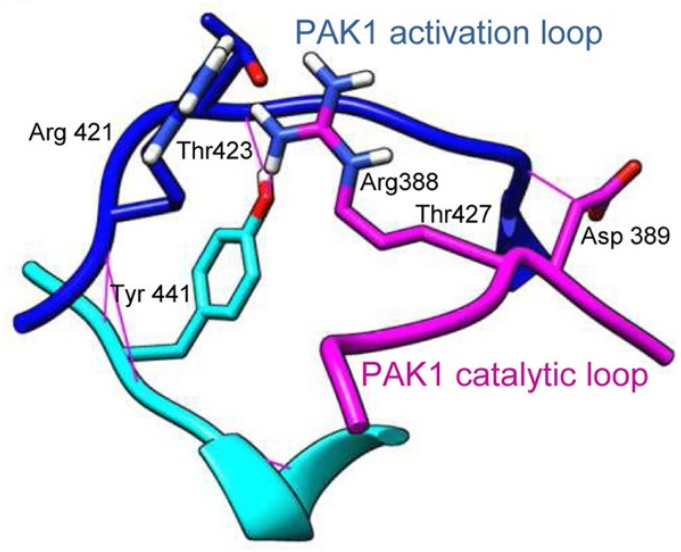

Figure 4 (See legend on next page.) 
(See figure on previous page.)

Figure 4 TQ induces early upregulation of ERK1/2 and the formation of a PAK1-ERK1/2 complex. A. TQ treated cells were assessed for ERK1/2 activity. Data is presented as fold activity normalized to control activity. Each value is the mean \pm SD of two independent experiments each done in duplicates. B. Cells pretreated for 1 hour with $10 \mu \mathrm{M}$ IPA-3 were incubated with $40 \mu \mathrm{M}$ TQ and cell pellets were collected after 1, 3, 6 and 24 hours. Lysates were immunoblotted for pERK1/2 and total ERK1/2. GAPDH was used as loading control. $\mathbf{C}$. Box plot analysis of the percentage of tumor cells expressing nuclear pERK1/2 in mouse xenografts after TQ treatment. $n$ represents the number of investigated mouse tissues in each group. *5 corresponds to a sample outlayer. D. Cell lysates stimulated with $60 \mu \mathrm{M}$ TQ for 10, 45 minutes, 1 and 24 hours were immunoprecipitated for PAK1 (upper panel) and ERK1/2 (lower panel) and blotted against total PAK and ERK1/2. IgG bands were used as loading control. Data shown are representative of two independent experiments. E. Cells transfected with the PAK1wt vector and the T423E mutant vector were exposed to 24 hours of $100 \mu \mathrm{M} \mathrm{TQ} .30 \mu \mathrm{g}$ of proteins was immunoblotted against pERK1/2. *indicates the omission of intermediate samples. F. Cells transfected or not with T212A and T212E mutants of PAK1 were treated with $100 \mu \mathrm{M} \mathrm{TQ}$. Lysates were immunoblotted against pPAK ${ }^{\text {Thr } 423}$. Data shown are representative of two independent experiments. G. Model of PAK1 activation (in dark blue) and catalytic loop (purple) presenting the different amino acids of interest. The kinase domain in PAK1 (residues 249-545) is where T423 resides. $\mathbf{H}$. Model of PAK1 activation (in dark blue) and catalytic loop (purple) in the presence of TQ showing rearrangements in the main activation loop under TQ. There are additional hydrogen bonds in the catalytic loop region involving residues Arg388 and Arg421 which are known to interact with Thr423 for the catalytic activity.

disrupted under IPA-3 this might explain the slight increase in $\mathrm{pPAK} 1^{\mathrm{Thr} 212}$ levels when TQ is combined with IPA-3 (Figure 3F).

From these findings we propose a functional relation between both phosphorylation sites of PAK1. Indeed, T212A mutant induced a significant increase in pPAK $1^{\text {Thr423 }}$ levels whereas the hyperphosphorylated T212E mutant showed a lesser extent of increase (Figure 4E). As presented in Additional file 5: Table S2, TQ binds in the vicinity of Thr212 and no binding occurs next to the 423 site. Therefore we speculate that the chain reaction orchestrated by TQ starts at Thr212 site, which correlates with the western blot pattern (Figure 2A). Furthermore, T423E resulted in a decrease in ERK1/2 phosphorylation (Figure 4F) suggesting an impaired interference of Thr423 residue with the kinase domain of PAK1 under TQ treatment. We analysed the structural changes induced by TQ on PAK1 catalytic site and activation loop. Figure 4G and Figure $4 \mathrm{H}$ depict the structural conformation of the catalytic domain of PAK1 in the absence (Figure 4G) or presence of TQ (Figure $4 \mathrm{H}$ ). The kinase domain shows a root-mean-square deviation of $0.38 \AA$ accompanied by rearrangements in the main activation loop. Hydrogen bond analysis (Additional file 8: Table S3) showed that a higher number of hydrogen bonds are formed in the catalytic loop region in the presence of TQ involving residues Arg388 and Arg421 which are known to interact with Thr423 for the catalytic activity. Finally this results in a disturbed interaction between the Thr423 site and the catalytic kinase domain which inhibits the PAK1 kinase activity and its prosurvival signaling (Figure 6). There are three other lines of evidence for this hypothesis: first, early TQinduced ERK1/2 activation is inhibited when PAK1 ${ }^{\text {Thr423 }}$ is maximally phosphorylated at $24 \mathrm{~h}$. Second, when IPA-3 is combined with TQ there is a decrease in Thr423 phosphorylation at early time points accompanied by a significant upregulation of pERK1/2 levels that confirms an early activation of MEK-ERK signaling. The lack of inhibition of pPAK $1^{\text {Thr423 }}$ at $24 \mathrm{~h}$ is closely associated with a decrease in prosurvival ERK1/2 activation and enhanced apoptosis induction at $24 \mathrm{~h}$. This can be explained by another structural modeling showing that TQ has the ability to effectively bind to the autoregulatory domain of PAK1 preventing IPA-3 ability to interrupt the interaction between Cdc42 and pPAK $1^{\text {Thr423 }}$. Third, the pPAK $1^{\text {Thr212 }}$ upregulation is not as dramatic as the pERK1/2 activation after combined TQ and IPA-3 treatment reinforcing the inhibitory loop for PAK1 activation. Although pERK1/2 should disappear completely by the higher level of pPAK $1^{\text {Thr } 423}$ at $24 \mathrm{~h}$, it is worth mentioning that other secondary kinase loops could be at play. Consequently the phosphorylation status of Thr423 and PAK1 kinase activity is affected by TQ proving the experimental observations reported here.

\section{Conclusions}

PAK1 has been described as a scaffold for ERK1/2/MEK to recruit MEK to RAF at the membrane [32] thus facilitating signaling through the ERK1/2 pathway [26,33]. We have shown previously a prosurvival function of ERK1/2 under TQ, since inhibition of ERK1/2 by the MEK inhibitor PD98059 resulted in enhanced apoptosis [8]. In the present study and for the first time we document that a small natural molecule, TQ, directly binds to PAK1/ERK kinase complex, induces considerable conformational changes of PAK1 and interrupts its scaffold function. Upon TQ the interference of Thr423 phosphorylation with the kinase domain is disrupted inhibiting the PAK1 kinase activity and its prosurvival signaling [23]. TQ-induced loss of ERK1/2 dependent phosphorylation at Thr212 of PAK1 provides another negative feedback of prosurvival PAK1/MEK/ERK1/2 signaling. The loss of nuclear pERK1/2 in TQ-treated mouse xenografts confirms the in vivo relevance of our finding. Overall, our approach allowed an identification of several novel TQ targets which could be used in the future to evaluate the therapeutic benefit of combination therapies. 


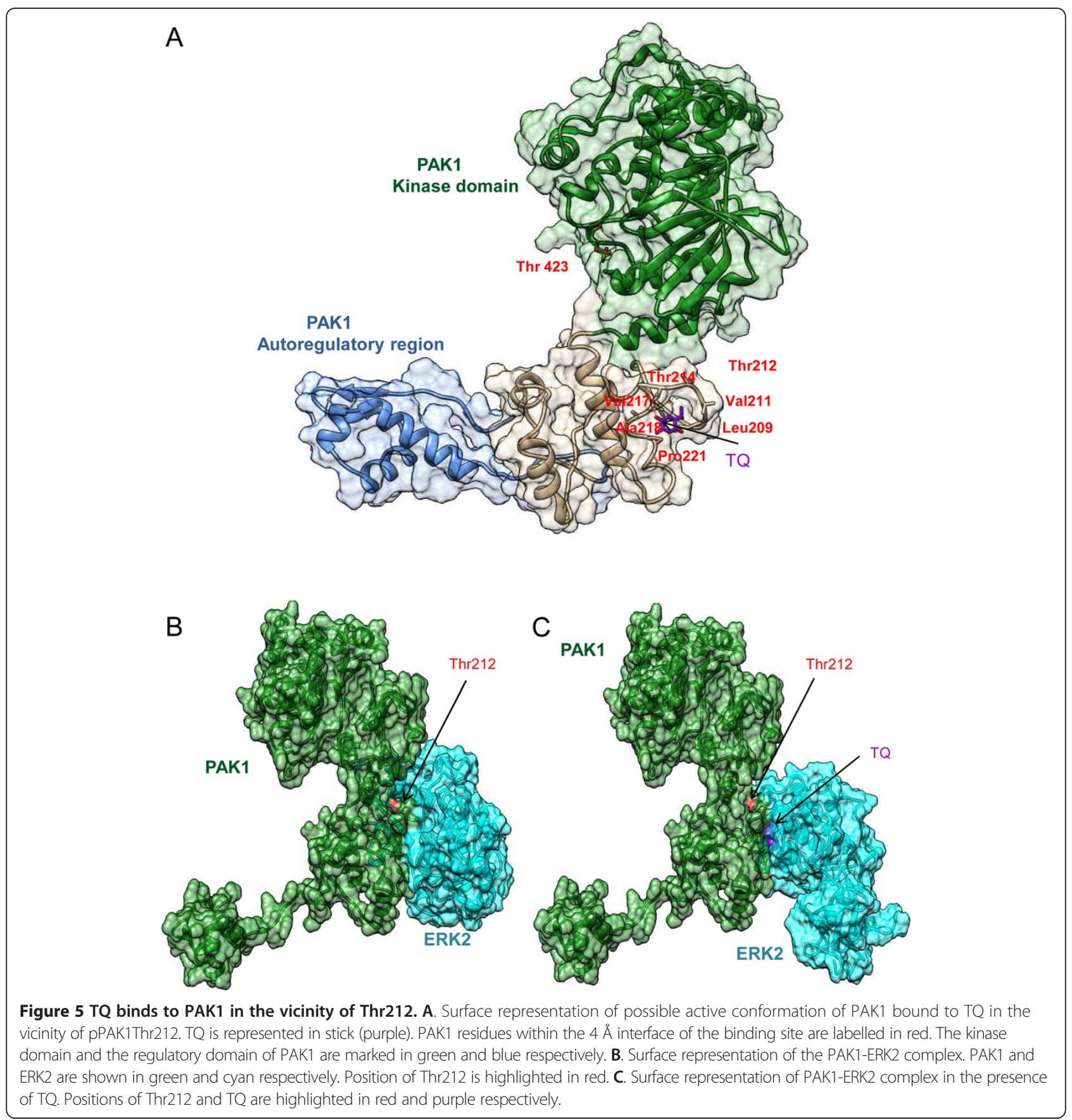

\section{Methods}

\section{Cell lines and reagents}

Human colon carcinoma HCT116wt, DLD-1 and HT29 cells were grown in RPMI 1640 medium (PAA Laboratories $\mathrm{GmbH}$, Pasching Austria) supplemented with 10\% fetal bovine serum (FBS) and 1\% penicillin-streptomycin (PANTM Biotech $\mathrm{GmbH}$, Germany) and kept at $37^{\circ} \mathrm{C}$ in a humidified incubator (95\% air, 5\%CO2). Cells were treated at $50 \%$ confluency with 40 or $60 \mu \mathrm{M}$ TQ (SigmaAldrich) dissolved in DMSO (final concentration less than $0.1 \%$ ) and collected at different time points. PAK1 inhibition was performed by preincubating the cells with $10 \mu \mathrm{M}$ IPA-3 (Sigma-Aldrich) for 1 hour.

\section{Peptide Array PepChip Kinomics v2}

HCT116wt cells $\left(1.5 \times 10^{5} / \mathrm{ml}\right)$ were treated with $40 \mu \mathrm{M}$ TQ and collected after 24 hours. Proteins were extracted and shipped to manufacturer (Pepscan, Netherland) according to manufacturer protocol. Briefly, cell pellets were lysed (20 mM Tris- $\mathrm{HCl}$ (pH 7.5), $150 \mathrm{mM} \mathrm{NaCl}$, 

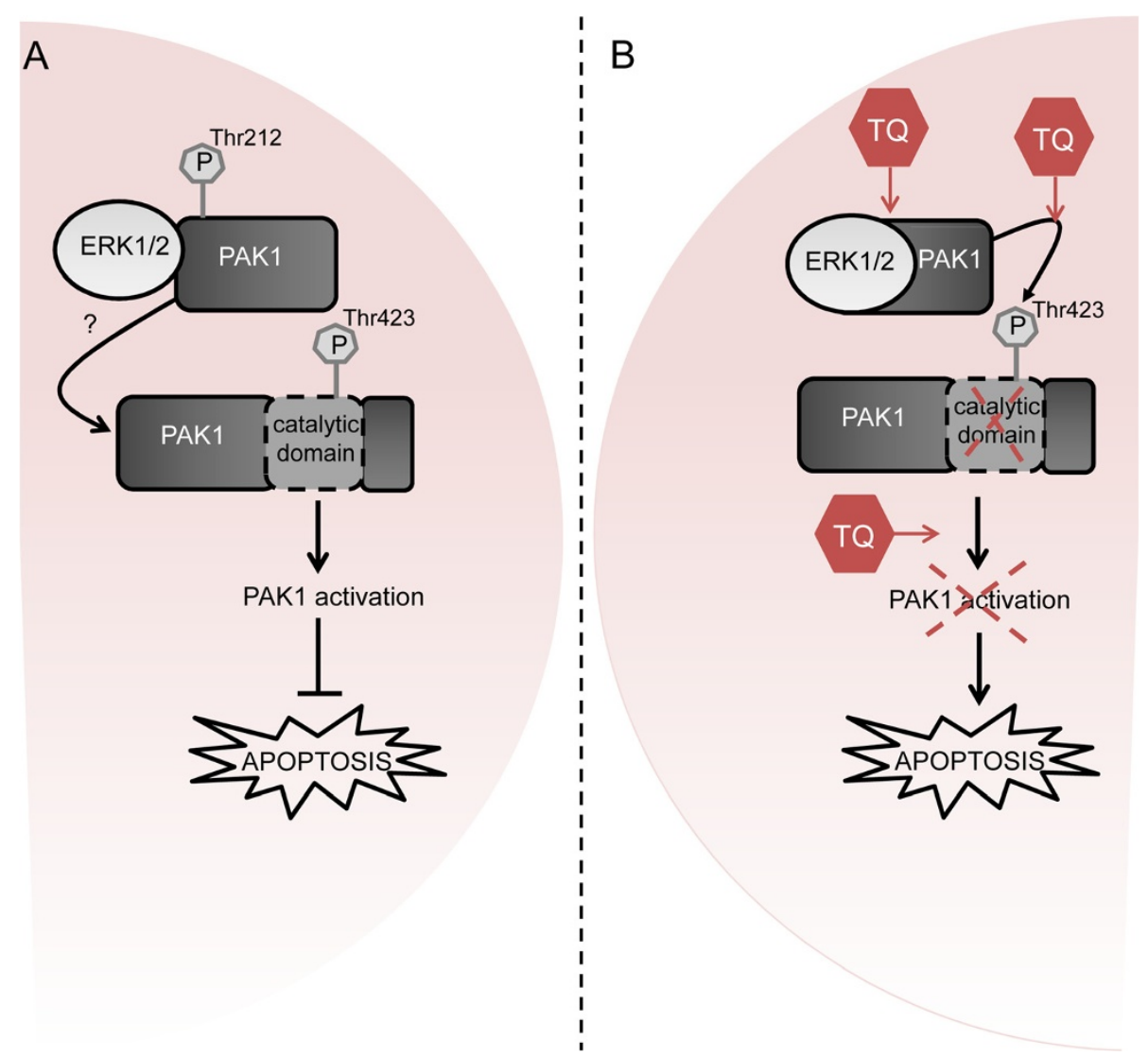

Figure 6 TQ induces changes in the PAK1-ERK1/2 complex conformation inhibiting the prosurvival role of PAK1. A. Without TQ, in cancer cells, ERK2 phosphorylates PPAK $1^{\text {Thr212 }}$ (I). While an interaction between PPAK $1^{\text {Thr } 212}$ and PPAK $1^{\text {Thr } 423}$ is so far not reported (II), pPAK1 $1^{\text {Thr } 423}$ is known to induce the catalytic activity of PAK1 (III) thus leading to the activation of the prosurvival ERK1/2 pathway (IV). B. Upon TQ we observed massive conformational changes of PAK1 disrupting its scaffold function in prosurvival PAK1/MEK/ERK1/2 signaling and leading to the following modified signaling: ERK1/2-PAK1 binding is reinforced preventing PPAK1 ${ }^{\text {Thr212 }}$ phosphorylation by ERK1/2 (I). This leads to an increased phosphorylation at the Thr423 site (II) which impairs the interference with the catalytic domain of PAK1 and prevents PAK1 activation (III) finally resulting in apoptosis induction (IV).

1 mM EDTA, 1 mM EGTA, 1\% Triton X-100, 2.5 mM sodium pyrophosphate, $1 \mathrm{mM}$ beta-glycercophosphate, $1 \mathrm{mM}$ sodium orthovanadate (Na3VO3), $1 \mathrm{mM} \mathrm{NaF}$, Roche Complete protease inhibitor cocktail). After sonication, the lysates were spin down and snap frozen before being shipped to the manufacturer. The concentration of the samples was determined using Bradford Protein Assay (Bio-Rad, Hercules, CA). Samples were then hybridized on PepChip Kinomics v2 chip and the kinome profiling was performed by the Pepscan Company. The peptide array was done with samples obtained from two independent experiments and every sample was spotted two times on the array.

Array Analysis software Ingenuity pathway analysis (IPA) Peptide array data was analyzed by Ingenuity pathway analysis software (IPA, version 9.0, Ingenuity (C) Systems, www.ingenuity.com, Mountain View, CA, USA). The data set contained upregulated proteins (fold-change $\geq 2$ after 24 hours of $40 \mu \mathrm{M}$ TQ treatment) identified by the pepscan peptide array and their protein ID number. Statistical significance of the different pathways obtained by IPA was calculated using a right-tailed Fisher's Exact test [34]. Pathways with a p-value $\leq 0.05$ were selected. WebLogo v3 application (http://weblogo.threeplusone. $\mathrm{com} /$ ) was used to analyze the phosphorylation consensus motifs of all the kinases and proteins identified by the array.

\section{Pathway Annotation Clustering}

The probable pathways by which the 50 candidate proteins, with fold-change $\geq 2$ after 24 hours of $40 \mu \mathrm{M}$ TQ treatment, could interfere were predicted using DAVID bioinformatics tool (http://david.abcc.ncifcrf.gov) [35, 36]. For pathway mapping, Uniprot IDs of differentially phosphorylated proteins were submitted to the DAVID web 
resource with colorectal cancer specific proteins from Human Protein Atlas (http://www.proteinatlas.org/) as background. Pathway predictions were made by including the subset pathway databases: KEGG, Panther, Biocarta, Reactome and BBID followed by pathway annotation clustering.

\section{Western blotting}

HCT116wt, DLD-1 and HT29 cells were grown to 50\% confluency and treated with $40 \mu \mathrm{MTQ}$ and harvested over different time points. The cells were then lysed with RIPA lysis buffer (150 mM NaCl, 0.5\% DOC, 0.1\% SDS, $1 \%$ NP40, $50 \mathrm{mM}$ Tris $\mathrm{pH} 8$ ) containing a cocktail of protease inhibitors. The protein concentration of all samples was determined by by DC BioRad protein assay kit (BioRad Laboratories, Hercules, CA) using bovine serum albumin as standard. Total proteins $(50 \mu \mathrm{g} / \mathrm{sam}$ ple) were separated on an 8-12\% SDS polyacrylamide gel and transferred to nitrocellulose membrane by blotting. After blocking with 5\% non-fat dry milk in TBST buffer, membranes were incubated with primary antibody at $4^{\circ} \mathrm{C}$ overnight, washed three times, with TBST buffer, and incubated again with the corresponding HRP-conjugated secondary antibody at room temperature for $1 \mathrm{~h}$. The membranes were then washed with TBST buffer and protein bands were detected by enhanced chemiluminescence. PAK1, ERK1/2, pERK1/2 and PARP were purchased from Cell signaling; pPAK $^{\text {Thr212 }}$ and pPAK $^{\text {Ser144 }}$ from Abcam and pPAK ${ }^{\text {Thr423 }}$ from Abgent. Densitometric analysis was performed for all western blots using ImageJ $1.45 \mathrm{~s}$ software.

\section{Immunoprecipitation}

Cells treated with $60 \mu \mathrm{M}$ TQ for 10, 45, 60 minutes and 24. hours were collected and lysed using RIPA buffer supplemented with proteases and phosphatases inhibitors. Immunoprecipitiation was performed using the Dynabeads Protein G magnetic separation KIT as per manufacturer protocol (Invitrogen). After incubating the beads with $600 \mu \mathrm{g}$ of proteins, they were incubated with anti-PAK1 and anti-ERK1/2 antibodies. The precipitated lysates were then loaded into SDS-PAGE gels and immunoblotted against total PAK1 and ERK1/2.

\section{Plasmids and siRNA transfections}

Plasmids (PAK1wt, K299R, T212E, T212A, T423E) were a gift from Prof. Jonathan Chernoff (Fox Chase Cancer Center, 333 Cottman Avenue, Philadelphia). Cells seeded in 6-well plates were transfected at 90\% confluency with $1 \mu \mathrm{g}$ of the different plasmids for 6 hours, using Invitrogen Lipofectamine 2000 according to manufacturer instructions. Afterwards cells were treated with $100 \mu \mathrm{M}$ TQ (due to the high cellular density) and collected after
24 hours. Cell lysates were then used for Western blotting analysis.

PAK1 and scrambled siRNA reagents were purchased from Thermo Fisher Scientific (Dharmacon RNAi Technologies). Lipofectamine RNAiMAX reagent was used to transfect HCT116 cells with $10 \mu \mathrm{M}$ siRNA, according to manufacturer's instructions. The next day the transfected cells were split and 50\% confluent plates were treated with $60 \mu \mathrm{M} \mathrm{TQ}$. Cell lysates were then used for Western blotting analysis.

\section{Structural analysis by docking}

To understand the interaction between PAK 1 and TQ, we modeled the structure of PAK1 and performed molecular docking with TQ using the Schrodinger suite (Maestro, version 9.3, Schrodinger, Inc, New York, NY, 2012). A model of the possible active state conformation of PAK1 was obtained by integrating the available crystal structures of the autoinhibitory domain 78-147(PDB ID: 1F3M) [27] and the kinase domain 250-542(PDB ID: 3Q52) [28] of PAK1 and a threaded model of the region corresponding to $148-249$ using ITASSER $[29,30]$. The possible ligand binding sites in PAK1 was analyzed using the SiteMap module (SiteMap, version 2.6, Schrödinger, Inc., New York, NY, 2012) of the Schrodinger suite. In order to analyze the binding mode of TQ near to Thr212 site, grids were generated focusing on Thr212 site and the interacting residues were identified. To study the interaction details of PAK1 and ERK2, the crystal structure of ERK2 available with PDB ID:2ERK [31] was docked to the TQ bound and unbound conformations of PAK1 using ClusPro $[37,38]$. The energies of the complexes were determined through energy minimization using AMBER11 [39] . Crystal structure of the autoinhibited dimer of PAK1 (PDB ID: $1 F 3 M)$ was used to understand the binding mode of IPA-3 on PAK1 [29]. The structural coordinates of the residues (416-422), missing in the PDB, belong to the kinase activation segment of PAK1 and were modeled using Modeller9v12 [40] . IPA-3 was then docked to the autoregulatory region of PAK1 (autoinhibited conformation). To analyze the combined effect of TQ and IPA-3 on PAK1, TQ was docked to the IPA-3 bound conformation of PAK1. All the dockings were performed using the extra precision mode of the Glide program of Schrodinger (Glide, version 5.8, Schrödinger, Inc., New York, NY, 2012). The structures of TQ and IPA-3 were obtained from the PubChem database. Protein and ligand structures for docking were prepared using Protein Preparation Wizard and LigPrep utilities of Schrodinger (LigPrep, version 2.5, Schrödinger, Inc., New York, NY, 2012). All renderings were done using Chimera 1.8 [41].

\section{Kinase Activity assay}

Multi-kinase ELISA array was performed as per the manufacturer protocol (Symansis). Briefly, Cells treated with 
$40 \mu \mathrm{M}$ TQ were collected after 1, 3, 6, 24 hours and lysed with 1X denaturing cell lysis buffer (Symansis CLB001). $30 \mu \mathrm{g}$ of proteins were loaded on pre-coated strips with antibodies corresponding to the investigated kinases. After several washing and hybridization steps, absorbance of each well was measured at $450 \mathrm{~nm}$ using VICTORTM X3 multilabel reader.

\section{Cell Viability assay}

Cellular viability was measured by crystal violet staining. HCT116wt $\left(3.75 \times 10^{4} / \mathrm{ml}\right)$ cells were seeded in 96 well plate and treated with $40 \mu \mathrm{M}$ TQ and/or 1-50 $\mu \mathrm{M}$ IPA-3 for 24 hours. The treated cells were washed once with PBS, fixed for $15 \mathrm{~min}$ in a crystal violet solution $(0.5 \%$ crystal violet in $20 \%$ methanol) at room temperature, then washed twice with water and air-dried. The stained cells were solubilized with methanol for 15 min with mild agitation. Absorbance was measured at $595 \mathrm{~nm}$ using VICTORTM X3 multilabel reader. $\mathrm{IC}_{50}$ values were calculated using EXCEL 2010. Statistical analysis was performed using SPSS version 19. One tailed Student T-Test was performed by comparing 2 samples assuming that they have equal variances.

\section{Annexin V/Propidium lodide staining}

Apoptosis was measured using Annexin V/PI co-staining. HCT116wt cells $\left(1.5 \times 10^{5} / \mathrm{ml}\right)$ were pretreated with IPA$3(10 \mu \mathrm{M})$ for 1 hour then treated with TQ $(40 \mu \mathrm{M})$ for 24 hours. After collection, cells were centrifuged at $200 \mathrm{~g}$ for $5 \mathrm{~min}, 4^{\circ} \mathrm{C}$ and washed with $1 \mathrm{X}$ PBS. The pellet was resuspended in $100 \mu \mathrm{l}$ Annexin-V-Fluos labeling solution $(10 \mu \mathrm{l}$ annexin reagent and $10 \mu \mathrm{l}$ PI solution in $150 \mu \mathrm{l}$ incubation buffer (according to manufacturer, Roche). The samples were incubated for $7 \mathrm{~min}$ in the dark, at room temperature then $100 \mu \mathrm{l}$ incubation buffer was added. The cellular fluorescence was then measured using a Fluorescence Activated Cell Sorter (FACS) flow cytometer (BDFACS CantoTM II). Each sample was collected as 20,000 ungated events and the different cell populations were determined using FlowJo software (FlowJo7.6.5).

\section{Immunohistochemistry}

Immunohistochemistry (IHC) was performed on available paraffin fixed tissue blocks from a xenograft experiment [10] to detect the expression of pERK1/2. Rehydration of tissue sections was performed in descending concentrations solutions of ethanol (96\% to $70 \%$ ). Antigen was retrieved by heating in a pressure cooker $(1 \mathrm{mmol} / \mathrm{L}$ Tris-EDTA buffer, $\left.120^{\circ} \mathrm{C}, 5 \mathrm{~min}\right)$. The slices were incubated in blocking solution (Dako, Glostrup, Denmark) to prevent nonspecific binding sites. Next pERK1/2 (1:2000) primary antibody was added to the slices and incubated for $30 \mathrm{~min}$ at room temperature. The sections were then washed with washing buffer (Dako) and incubated with EnVision + System horseradish peroxidase-linked secondary antibody (goat anti- rabbit, Dako) at room temperature for 30 min. Positive immunoreactivity was detected using diaminobenzidine + (Dako). Positive and negative IHC controls were included in this study. Percentage and intensity of positively stained epithelial cells (cytoplasmic versus nuclei) was quantified and scored by an expert pathologist (T.T.R.). Statistical analysis was performed using SPSS. Two tailed student $\mathrm{t}$-test was performed by comparing 2 samples assuming that they have equal variances.

\section{Additional files}

\begin{abstract}
Additional file 1: Table S1. Known TQ targets identified by the
peptide array.

Additional file 2: Figure S1. TQ did not induce changes in the main kinases affected by IPA-3. Cells treated with $40 \mu \mathrm{M}$ TQ were collected after 1, 3, 6 and 24 hours. Untreated cells were used as a control. $30 \mu \mathrm{g}$ of proteins per well were used to assess the activity of AKT2, GSKa, GSKB and p38. Data is presented as fold activity normalized to control activity. Each value is the mean \pm SD of two independent experiments each done in duplicates.

Additional file 3: Figure S2. TQ show low toxicity on normal intestinal cells. HCT116 (A) and HCEC (B) cells were treated with different TQ concentrations $(0-100 \mu \mathrm{M})$ for 24 hours to define the $I C_{50}$ value. Cell viability was assessed by crystal violet staining. Data are presented as percentage of control. Each value is the mean \pm SD of three independent experiments done in quadruplicates.
\end{abstract}

Additional file 4: Figure S3. IPA-3 and TQ bind to the autoinhibited dimer conformation of PAK1. A. Model of IPA-3 bound autoinhibited dimer conformation of PAK1 (PDB id:1 kx5). Autoregulatory region (blue and green) and kinase domain (pink and blue) of PAK1 dimer are shown. IPA-3 is shown in red using a stick representation and the residues interacting with IPA-3 labeled in black. B. Model of IPA-3 and TQ bound autoinhibited dimer conformation of PAK1. TQ is shown in purple as a stick representation. The residues interacting with TQ are labeled in black. The rendering follows color legend used in $\mathbf{A}$.

Additional file 5: Table S2. PAK1 residues interference with TQ and/or IPA-3.

Additional file 6: Figure S4. TQ induces down regulation of prosurvival $\mathrm{pERK} 1 / 2$ in vivo. Mouse xenograft experiment showing $\mathbf{A}$.

Immunohistochemical detection of pERK1/2 on tumors of control (left) and TQ treated (right) animals. B. Box plot analysis of the percentage of tumor cells expressing cytoplasmic pERK1/2 after TQ treatment. $n$ represents the number of investigated mouse tissues in each group. *16 corresponds to sample 16 being an outlayer.

Additional file 7: Figure S5. TQ induces the phosphorylation of PPAK $1^{\text {Thr212 }}$ before the phosphorylation of pERK1/2. Cells treated with $60 \mu \mathrm{M}$ TQ were collected after 10, 15, 30, 45, 60 and 90 min. untreated cells were used as control. $30 \mu \mathrm{g}$ of proteins were immunoblotted against pPAKThr212 and pERK1/2. GAPDH was used as loading control. Data shown are representative of two independent experiments.

Additional file 8: Table S3. Hydrogen bonds formed at the PAK1 catalytic site in the absence and presence of TQ.

\section{Abbreviations}

TQ: Thymoquinone; AKT/PKB: Protein kinase B; ERK: Extracellular-signal-regulated kinase; PIk1 PBD: Serine/threonine kinase Polo-like kinase 1; PAK1: p21 protein (Cdc42/Rac)-activated kinase 1; IPA-3: 1,1'-disulfanediyldinaphthalen-2-ol.

\section{Competing interests}

The authors declare that they have no competing interests. 


\section{Authors' contributions}

CEB performed all in vitro assays; she was involved in conception and design, development and methodology, acquisition of data, analysis and interpretation of data, writing and revision of the manuscript. VM performed the docking and clustering analysis and revised the manuscript. FBF performed the Ingenuity pathway analysis. SM performed docking and pathway clustering. TTR performed the IHC scoring, critically discussed and revised the manuscript. HGM was involved in data analysis and interpretation, writing and revision of the manuscript. RSS is the corresponding author as well as the study supervisor; she was involved in conception and design of this work, development and methodology, analysis and interpretation of data, writing and revision of the manuscript. All authors read and approved the final manuscript.

\section{Acknowledgement}

We would like to thank Krista Winkelmann for immunohistochemical staining assistance and Mariana Bublik and Anna Zarling for technical assistance. Funding

This study was supported by the Deutsche Forschungsgemeinschaft (SCHN477/12-1), to RSS and HGM.

\section{Author details \\ ${ }^{1}$ Experimental Tumorpathology, Institute of Pathology, Friedrich-Alexander University Erlangen-Nürnberg (FAU), Erlangen, Germany. ${ }^{2}$ School of Chemical and Biotechnology of the SASTRA University, Thanjavur, India. ${ }^{3}$ Department of Pediatrics and Adolescent Medicine, University of Erlangen-Nürnberg, Erlangen, Germany. ${ }^{4}$ Department of Biology, American University of Beirut, Beirut, Lebanon.}

Received: 17 April 2014 Accepted: 25 August 2014

Published: 29 August 2014

\section{References}

1. Cunningham D, Atkin W, Lenz HJ, Lynch HT, Minsky B, Nordlinger B, Starling N: Colorectal cancer. Lancet 2010, 375:1030-1047.

2. Schneider-Stock R, Fakhoury IH, Zaki AM, El-Baba CO, Gali-Muhtasib HU: Thymoquinone: fifty years of success in the battle against cancer models. Drug Discov Today 2014, 19:18-30.

3. Nessa MU, Beale P, Chan C, Yu JQ, Huq F: Synergism from combinations of cisplatin and oxaliplatin with quercetin and thymoquinone in human ovarian tumour models. Anticancer Res 2011, 31:3789-3797.

4. Woo CC, Kumar AP, Sethi G, Tan KH: Thymoquinone: potential cure for inflammatory disorders and cancer. Biochem Pharmacol 2012, 83:443-451.

5. Jafri SH, Glass J, Shi R, Zhang S, Prince M, Kleiner-Hancock H: Thymoquinone and cisplatin as a therapeutic combination in lung cancer: In vitro and in vivo. J Exp Clin Cancer Res 2010, 29:87.

6. Banerjee S, Kaseb AO, Wang Z, Kong D, Mohammad M, Padhye S, Sarkar FH, Mohammad RM: Antitumor activity of gemcitabine and oxaliplatin is augmented by thymoquinone in pancreatic cancer. Cancer Res 2009, 69:5575-5583.

7. Lei X, Lv X, Liu M, Yang Z, Ji M, Guo X, Dong W: Thymoquinone inhibits growth and augments 5-fluorouracil-induced apoptosis in gastric cancer cells both in vitro and in vivo. Biochem Biophys Res Commun 2012, 417:864-868.

8. El-Najjar N, Chatila M, Moukadem H, Vuorela H, Ocker M, Gandesiri M, Schneider-Stock R, Gali-Muhtasib H: Reactive oxygen species mediate thymoquinone-induced apoptosis and activate ERK and JNK signaling. Apoptosis 2010, 15:183-195.

9. Gali-Muhtasib H, Kuester D, Mawrin C, Bajbouj K, Diestel A, Ocker M, Habold C, Foltzer-Jourdainne C, Schoenfeld P, Peters B, et al: Thymoquinone triggers inactivation of the stress response pathway sensor CHEK1 and contributes to apoptosis in colorectal cancer cells. Cancer Res 2008, 68:5609-5618.

10. Gali-Muhtasib H, Ocker M, Kuester D, Krueger S, El-Hajj Z, Diestel A, Evert M, El-Najjar N, Peters B, Jurjus A, et al: Thymoquinone reduces mouse colon tumor cell invasion and inhibits tumor growth in murine colon cancer models. J Cell Mol Med 2008, 12:330-342.

11. Gali-Muhtasib H, Diab-Assaf M, Boltze C, Al-Hmaira J, Hartig R, Roessner A, Schneider-Stock R: Thymoquinone extracted from black seed triggers apoptotic cell death in human colorectal cancer cells via a p53-dependent mechanism. Int J Oncol 2004, 25:857-866.
12. Gali-Muhtasib HU: Abou Kheir WG, Kheir LA, Darwiche N, Crooks PA: Molecular pathway for thymoquinone-induced cell-cycle arrest and apoptosis in neoplastic keratinocytes. Anticancer Drugs 2004, 15:389-399.

13. Yi T, Cho SG, Yi Z, Pang X, Rodriguez M, Wang Y, Sethi G, Aggarwal BB, Liu $M$ : Thymoquinone inhibits tumor angiogenesis and tumor growth through suppressing AKT and extracellular signal-regulated kinase signaling pathways. Mol Cancer Ther 2008, 7:1789-1796.

14. Woo CC, Hsu A, Kumar AP, Sethi G, Tan KH: Thymoquinone inhibits tumor growth and induces apoptosis in a breast cancer xenograft mouse model: the role of p38 MAPK and ROS. PLOS One 2013, 8:e75356.

15. Attoub S, Sperandio O, Raza H, Arafat K, Al-Salam S: Al Sultan MA, Al Safi M, Takahashi T, Adem A: Thymoquinone as an anticancer agent: evidence from inhibition of cancer cells viability and invasion in vitro and tumor growth in vivo. Fundam Clin Pharmacol 2013, 27:557-569.

16. Siveen KS, Mustafa N, Li F, Kannaiyan R, Ahn KS, Kumar AP, Chng WJ, Sethi G: Thymoquinone overcomes chemoresistance and enhances the anticancer effects of bortezomib through abrogation of NF-kappaB regulated gene products in multiple myeloma xenograft mouse model. Oncotarget 2014, 5:634-648.

17. Li F, Rajendran P, Sethi G: Thymoquinone inhibits proliferation, induces apoptosis and chemosensitizes human multiple myeloma cells through suppression of signal transducer and activator of transcription 3 activation pathway. Br J Pharmacol 2010, 161:541-554.

18. Sethi G, Ahn KS, Aggarwal BB: Targeting nuclear factor-kappa B activation pathway by thymoquinone: role in suppression of antiapoptotic gene products and enhancement of apoptosis. Mol Cancer Res 2008, 6:1059-1070.

19. Yin Z, Song Y, Rehse PH: Thymoquinone blocks pSer/pThr recognition by Plk1 Polo-box domain as a phosphate mimic. ACS Chem Biol 2013, 8:303-308.

20. Fabbro D, Cowan-Jacob SW, Mobitz H, Martiny-Baron G: Targeting cancer with small-molecular-weight kinase inhibitors. Methods Mol Biol 2012, 795:1-34.

21. Zhao ZS, Lim JP, Ng YW, Lim L, Manser E: The GIT-associated kinase PAK targets to the centrosome and regulates Aurora-A. Mol Cell 2005, 20:237-249.

22. Eswaran J, Li DQ, Shah A, Kumar R: Molecular pathways: targeting p21activated kinase 1 signaling in cancer-opportunities, challenges, and limitations.

Clin Cancer Res 2012, 18:3743-3749.

23. Kichina JV, Goc A, Al-Husein B, Somanath PR, Kandel ES: PAK1 as a therapeutic target. Expert Opin Ther Targets 2010, 14:703-725.

24. Wong LL, Lam IP, Wong TY, Lai WL, Liu HF, Yeung LL, Ching YP: IPA-3 inhibits the growth of liver cancer cells by suppressing PAK1 and NFkappaB activation. PLoS One 2013, 8:e68843.

25. Zenke FT, King CC, Bohl BP, Bokoch GM: Identification of a central phosphorylation site in p21-activated kinase regulating autoinhibition and kinase activity. J Biol Chem 1999, 274:32565-32573.

26. Sundberg-Smith LJ, Doherty JT, Mack CP, Taylor JM: Adhesion stimulates direct PAK1/ERK2 association and leads to ERK-dependent PAK1 Thr212 phosphorylation. J Biol Chem 2005, 280:2055-2064.

27. Lei M, Lu W, Meng W, Parrini MC, Eck MJ, Mayer BJ, Harrison SC: Structure of PAK1 in an autoinhibited conformation reveals a multistage activation switch. Cell 2000, 102:387-397.

28. Wang J, Wu JW, Wang ZX: Structural insights into the autoactivation mechanism of p21-activated protein kinase. Structure 2011, 19:1752-1761.

29. Zhang Y: I-TASSER server for protein 3D structure prediction. BMC Bioinformatics 2008, 9:40.

30. Roy A, Kucukural A, Zhang Y: I-TASSER: a unified platform for automated protein structure and function prediction. Nat Protoc 2010, 5:725-738.

31. Canagarajah BJ, Khokhlatchev A, Cobb MH, Goldsmith EJ: Activation mechanism of the MAP kinase ERK2 by dual phosphorylation. Cell 1997, 90:859-869.

32. Wang Z, Fu M, Wang L, Liu J, Li Y, Brakebusch C, Mei Q: p21-activated kinase 1 (PAK1) can promote ERK activation in a kinase-independent manner. J Biol Chem 2013, 288:20093-20099.

33. Howe AK, Aplin AE, Juliano RL: Anchorage-dependent ERK signaling-mechanisms and consequences. Curr Opin Genet Dev 2002 12:30-35.

34. Zhan $X$, Desiderio DM: Signaling pathway networks mined from human pituitary adenoma proteomics data. BMC Med Genomics 2010, 3:13. 
35. Da Huang W, Sherman BT, Lempicki RA: Systematic and integrative analysis of large gene lists using DAVID bioinformatics resources. Nat Protoc 2009, 4:44-57.

36. Da Huang W, Sherman BT, Lempicki RA: Bioinformatics enrichment tools: paths toward the comprehensive functional analysis of large gene lists. Nucleic Acids Res 2009, 37:1-13.

37. Comeau SR, Gatchell DW, Vajda S, Camacho CJ: ClusPro: a fully automated algorithm for protein-protein docking. Nucleic Acids Res 2004, 32:W96-99.

38. Comeau SR, Gatchell DW, Vajda S, Camacho CJ: ClusPro: an automated docking and discrimination method for the prediction of protein complexes. Bioinformatics 2004, 20:45-50.

39. Gohlke H, Kiel C, Case DA: Insights into protein-protein binding by binding free energy calculation and free energy decomposition for the Ras-Raf and Ras-RalGDS complexes. J Mol Biol 2003, 330:891-913.

40. Sanchez R, Sali A: Comparative protein structure modeling. Introduction and practical examples with modeller. Methods Mol Biol 2000, 143:97-129.

41. Pettersen EF, Goddard TD, Huang CC, Couch GS, Greenblatt DM, Meng EC, Ferrin TE: UCSF Chimera-a visualization system for exploratory research and analysis. J Comput Chem 2004, 25:1605-1612.

doi:10.1186/1476-4598-13-201

Cite this article as: El-Baba et al:: Thymoquinone-induced conformational changes of PAK1 interrupt prosurvival MEK-ERK signaling in colorectal cancer. Molecular Cancer 2014 13:201.

\section{Submit your next manuscript to BioMed Central and take full advantage of:}

- Convenient online submission

- Thorough peer review

- No space constraints or color figure charges

- Immediate publication on acceptance

- Inclusion in PubMed, CAS, Scopus and Google Scholar

- Research which is freely available for redistribution 